\title{
Efficacy of Tenofovir in Patients with Acute Chronic Hepatitis B liver Failure
}

\author{
Dr. Sharker Mohammad Shahadat Hossain ${ }^{1 *}$, Dr. Mamun Al Mahtab ${ }^{2}$, Dr. Salimur Rahman ${ }^{3}$
}

${ }^{1}$ Dr. Sharker Mohammad Shahadat Hossain, Assistant Professor, Department of Hepatology, Kurmitola General Hospital, Dhaka, Bangladesh
${ }^{2}$ Dr. Mamun Al Mahtab, Professor, Department of Hepatology, Bangabandhu Sheikh Mujib Medical University (BSMMU), Dhaka, Bangladesh
${ }^{3}$ Dr. Salimur Rahman, Professor, Department of Hepatology, Bangabandhu Sheikh Mujib Medical University (BSMMU), Dhaka, Bangladesh

DOI: $10.36347 /$ sasjm.2020.v06i12.002

| Received: 17.11.2020 | Accepted: 28.11.2020 | Published: 04.12.2020

*Corresponding author: Dr. Sharker Mohammad Shahadat Hossain

Abstract

Original Research Article

Background: The effectiveness of nucleoside analogue (NA) treatment in patients with chronic hepatitis B (CHB) associated liver failure is still controversial. Severe lactic acidosis has been reported during entecavir (ETV) treatment in patients with impaired liver function. Aim: To investigate the rescuing efficacy and safety of ETV in patients with CHB-associated liver failure. Methodology: In this study a total of 32 acute on chronic Hepatitis B liver failure patients (age > 18 years with both sexes but male predominant) were included in Hepatology department of Bangabandhu Sheikh Mujib Medical University, Dhaka during January 2013 to December 2015. The patients were randomized into two groups: Tenofovir group $(\mathrm{N}=16)$ and Entecavir group $(\mathrm{n}=32)$ and followed at least for 03 months. Result: It was observed that more than two third (68.8\%) patients belonged to age $\leq 50$ years in tenofovir group. The mean age was found $43.8 \pm 13.1$ years in tenofovir. The mean difference was not statistically significant $(\mathrm{p}>0.05)$ of tenofovir. Altered level of consciousness was found $10(87.5 \%)$ in tenofovir group. Moderate ascites was found $11(68.8 \%)$ in tenofovir group. Encephalopathy was found $10(62.5 \%)$ in tenofovir group. The tenofovir was not statistically significant $(\mathrm{p}>0.05)$. It was observed that mean total countwas found $10580.0 \pm 4818.6 / \mathrm{mm}^{3}$ in tenofovir group Mean serum bilirubinwas found $19.8 \pm 7.4 \mathrm{mg} / \mathrm{dl}$ in tenofovir group. Mean Rank ALT was found 15.0 U/L in tenofovir group. Mean Rank AST was found 15.2 U/L in tenofovir group. Mean prothrombin time was found 22.1 \pm 3.3 second in tenofovir group. Mean international normalized ratio was found $1.9 \pm 0.3$ in tenofovir group. Mean serum albumin was found $2.1 \pm 0.6 \mathrm{gm} / \mathrm{dl}$ in tenofovir group. Mean serum creatinine was found $0.98 \pm 0.27 \mathrm{mg} / \mathrm{dl}$ in tenofovir group. Mean serum sodium was found $133.4 \pm 5.3 \mathrm{mmol} / \mathrm{l}$ in tenofovir. Mean serum potassium was found $4.1 \pm 0.7$

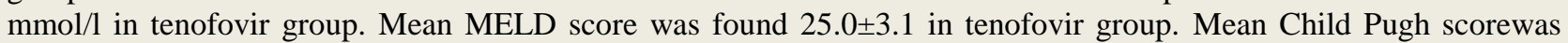
found $12.1 \pm 1.3$ in tenofovir group. The mean difference were not statistically significant $(\mathrm{p}>0.05)$ of tenofovir. HBeAg was found $12(37.5 \%)$ patients in tenofovir group. HBV DNA was found $16(50.0 \%)$ patients belonged to HBV DNA $>20000 \mathrm{IU} / \mathrm{ml}$ in tenofovir group. Mean Rank HBV DNA was found $16.8 \mathrm{IU} / \mathrm{ml}$ in tenofovir group. The in tenofovir was not statistically significant $(\mathrm{p}>0.05)$. Conclusion: For some people, Hepatatis B infection becomes chronic, meaning it lasts more than six months. Having chronic hepatitis B increases your risk of developing liver failure liver cancer or cirrhosis a condition that permanently scars of the liver. Tenofovir can treat hepatitis B very effectively in some people. In some situations, tenofovir is more effective. Research suggests tenofovir is a safe and effective long term reatment.

Keywords: HBV, Chronic hepatitis B, Efficacy, tenofovir.

Copyright (C) 2020 The Author(s): This is an open-access article distributed under the terms of the Creative Commons Attribution 4.0 International License (CC BY-NC 4.0) which permits unrestricted use, distribution, and reproduction in any medium for non-commercial use provided the original author and source are credited.

\section{INTRODUCTION}

Tenofovir can treat hepatitis B very effectively in some people. In some situations, tenofovir is more effective than adefovir and lamivudine. Research suggests tenofovir is a safe and effective long-term treatment for $\mathrm{HBV}$, especially for people who have developed resistance to lamivudine. Several antiviral medications - including entecavir (Baraclude), tenofovir (Viread), lamivudine (Epivir), adefovir (Hepsera) and telbivudine (Tyzeka) — can help fight the virus and slow its ability to damage your liver. These drugs are taken by mouth. Talk to your doctor about which medication might be right for you. Chronic hepatitis is inflammation of the liver that lasts at least 6 months. Common causes include hepatitis $\mathrm{B}$ and $\mathrm{C}$ viruses and certain drugs. Most people have no symptoms, but some have vague symptoms, such as a 
general feeling of illness, poor appetite, and fatigue. A large number of clinical studies have shown that chronic HBV persistent infection causes the dysfunction of innate and adaptive immune response involving monocytes/macrophages, dendritic cells, natural killer (NK) cells, T cells.

However, having an undetectable viral load doesn't mean you won't infected someone during unsafe sex. Even if a man has an undetectable viral load, studies show his semen still contains some HBV and can spread infection, though the risk is lower. Acute on chronic liver failure (ACLF) is currently recognized as a specific entity characterized by acute deterioration of liver function in the context of compensated or even decompensated, but hitherto stable, cirrhosis [1]. Chronic hepatitis B virus (HBV) infection is a serious health problem because of its worldwide distribution and its potential adverse sequelae, including cirrhosis and hepatocellular carcinoma (HCC) [2]. It was estimated that more than 200,000 and 300,000 chronic HBV carriers worldwide die of liver cirrhosis and HCC, respectively, each year [3]. On the other hand short term prognosis of patients with spontaneous severe acute exacerbation of CHB leading to ACLF-like presentation is extremely poor, with a high mortality ranging from $30 \%$ to $70 \%$. [4]. Tenofovirdisoproxilfumarate is an acyclic nucleotide analogue. Tenofovirdiphosphate inhibits the activity of HIV-1 reverse transcriptase and $\mathrm{HBV}$ reverse transcriptase by competing with the natural substrate deoxyadenosine 5'-triphosphate and after incorporation into DNA by DNA chain termination. Tenofovirdiphosphate is a weak inhibitor of mammalian DNA polymerases $\alpha, \beta$, and mitochondrial DNA polymerase $\gamma$. Tenofovir is water soluble. The oral bioavailability of tenofovir is approximately $25 \%$. Following oral administration of Tenofovir, maximum tenofovir serum concentrations are achieved within 0.5 to 1.5 hours.In vitro binding of tenofovir to human plasma or serum proteins is less than 0.7 and $7.2 \%$ respectively, over the tenofovir concentration range 0.01 to $25 \mathrm{ug} / \mathrm{ml}$. Tenofovir is eliminated by a combination of glomerular filtration and active tubular secretion. Following a single oral dose of Tenofovir the terminal elimination half-life of tenofovir is approximately 17 hours. Usual adult dose for chronic Hepatitis B is $300 \mathrm{mg}$ once a day. The optimum duration of treatment is not known. Tenofovir is an acyclic nucleotide analogue and is structurally similar to Adefovir. It is active against both wild type and LAM-resistant mutants of $\mathrm{HBV}$ and is superior to Adefivir in $\mathrm{HBeAg}$-negative and $\mathrm{HBeAg}$-positive treatment-naïve $\mathrm{CHB}$ patients [2]. It also demonstrated potent antiviral activity in patients with suboptimal response to Adefovir, mostly with prior LAM exposure. More than 2-log reduction in HBV DNA levels at 2 weeks of treatment was the only independent predictor of survival [2]. Hence, rapid suppression of HBV DNA despite at a time when the heightened immune response is ongoing can stabilize or halt disease progression, and thereby improves prognosis. The pharmacokinetics of tenofovir are altered in subjects with renal impairment. In subjects with creatinine clearance below $50 \mathrm{~mL} / \mathrm{min}$ or with end-stage renal disease (ESRD) requiring dialysis, Cmax, and AUC0- $\infty$ of tenofovir were increased. It is recommended that the dosing interval for Tenofovir be modified in patients with estimated creatinine clearance below $50 \mathrm{~mL} / \mathrm{min}$ or in patients with ESRD who require dialysis. Renal dose adjustments in adults are; If CrCL 30 to $49 \mathrm{ml} / \mathrm{min}$ : 300 mg orally every 48 hours, If CrCL 10 tO $29 \mathrm{ml} / \mathrm{min}$ : $300 \mathrm{mg}$ orally every 72 to 96 hours. No change in Tenofovir dosing is required in patients with hepatic impairment. Lactic acidosis has been reported with the use of nucleotide analogs, alone or in combination with other antiretrovirals. A majority of these cases have been in women. Obesity and prolonged nucleotide exposure may be risk factors. Severe acute exacerbations of hepatitis $B$ have been reported in patients who have suddenly discontinued tenofovir. Hepatic function should be monitored closely with both clinical and laboratory follow up for at least several months in patients who discontinue tenofovir. Treatment with Tenofovir should be suspended in any patient who develops clinical or laboratory findings suggestive of lactic acidosis. Creatinine clearance should be calculated in all patients before starting tenofovir and during treatment of tenofovir, patients at risk of or with a history renal dysfunction and patients with previous renal events while using adefovir. Tenofovir should be avoided in patients who are currently using or have recently used nephrotoxic drugs. Other most common possible adverse effect are nausea, vomiting, diarrhoea, abdominal pain, flatulence, dyspepsia, Less common are headache, asthenia, dizziness, myalgia, arthalgia, neutropenia, allergic reaction, skin rash and peripheral neuropathy.

\section{METHODOLOGY}

The study was carried out from January 2013 to December 2015 Randomized clinical trial at the Inpatient Department of the Department of Hepatology, BSMMU, while patients were admitted through the Outpatient Department of the same Department. Acute on chronic hepatitis B liver failure patients (age >18 years of both sexes) were enrolled as study population. Inclusion criteria: Age: > 18 years, Sex: both sexes, Bilirubin $\geq 5 \mathrm{mg} / \mathrm{dl}$, Coagulopathy (international normalized ratio $\geq 1.5$ ), Complicated by ascites and/or encephalopathy within 4 weeks. Patients with chronic liver disease due to HBV infection.

Acute insult by reactivation of $\mathrm{HBV}$ or $\mathrm{HBV}$ flare. Exclusion criteria: Age <18 years, Acute insult caused by HEV, HAV, drugs, alcohol etc. Decompensated cirrhosis of liver. Acute on chronic hepatitis B liver failure patient with undetected HBV DNA. Patients with chronic liver disease due to HCV infection, NASH etc. Coexistent hepatocellular 
carcinoma (HCC), Serum creatinine $>1.5 \mathrm{mg} / \mathrm{dl}$. Pregnancy Patients on antiviral drugs, Patients on immunomodulator therapy, Patients on cytotoxic/immunosuppressive therapy, Co-morbidity like heart failure, any malignancy, uncontrolled diabetes etc. Patients unwilling to take part in the study. Sampling technique: Purposive (judgment) sampling, Sample size: 32. Patient with clinical suspicion of ACLF were admitted in Department of Hepatology from Outpatient Department. The diagnosis of ACLF was confirmed after proper evaluation and investigations. The study was conducted fulfilling all criteria of good clinical practice according to the Declaration of Helsinki. Written informed consent in Bengali for inclusion into the trial was obtained from all study subjects. Shortly after admission, the patients were enrolled and randomized into two groups with one group receiving tenofovir and other group receiving entecavir. The potential benefits and risks of the use of tenofovir and entecevir and the non-availability of liver transplantation facilities were explained to them. Every alternate patient received tenofovir and entecavir respectively. Tablet tenofovir (300mg) was given orally daily to half of the patients while the other half received tablet entecavir $(0.5 \mathrm{mg})$ orally daily according to APASL ACLF Management Guideline of 2014. Both drugs were administered in empty stomach (at least 2 hours before or 2 hours after meals) along with standard medical therapy and the patients were followed up for 03 months. Permanent address, present address, mobile and land phone number of all patients were recorded and close liaison was maintained with all patients. Patients and/or their relatives were contacted over telephone and by post reminding of them of their follow up visits, in case they were not admitted in the Department of Hepatology, BSMMU at the time of a particular follow up. All adverse events were recorded describing their nature (local or systemic), intensity and the necessary treatment to relieve them according to WHO guidelines (WHO technical report series No. 850, 1995), the intensity degrees of which are as follows: No adverse reaction, Mild; it does not require treatment, Moderate; it requires treatment and disappears with treatment, Severe; it puts the patient's life in danger or produces death. It requires prolonged hospitalization, produces significant or persistent disability or congenital malformations. Dose modification of tenofovir and entecavir was done according to $\mathrm{CrCL}$ level in appropriate cases. In case of tenofovir group, If CrCL 30 to $49 \mathrm{ml} / \mathrm{min}$ : $300 \mathrm{mg}$ orally every 48 hours, If CrCL 10 to $29 \mathrm{ml} / \mathrm{min}: 300 \mathrm{mg}$ orally every 72 to 96 hours. In case of entecavir group with renal Impairment; if CrCL> 50 usual dose of entecavir was $0.5 \mathrm{mg}$ once daily, if CrCL 30 to $<50$, dose was 0.25 $\mathrm{mg}$ once daily or $0.5 \mathrm{mg}$ every 48 hours, if CrCL 10 to $<30$, dose was $0.15 \mathrm{mg}$ once daily, or $0.5 \mathrm{mg}$ every 72 hours. Close liaison was maintained with colleagues at Government hospitals (upozilla health complexes and sadar hospitals) closest to the residences of the study subjects as well as with colleagues of private hospitals, where they received treatment, had they fallen ill after discharge from the Department of Hepatology, BSMMU. Cause, time and date of death was recorded in case of every study subject who expired from the hospital records of Department of Hepatology, BSMMU or respective Government or private hospitals in case of deaths of every study subject. Data were collected using a preformed data collection sheet (questionnaire). Base line information was collected from the patient and/or their relatives. All information regarding clinical features was recorded in a data collection sheet. Fasting plasma glucose, alanine aminotransferase (ALT), aspartate aminotransferase (AST), total bilirubin, prothombin time (INR), serum albumin, serum creatinine, serum electrolyte, CBC and alpha fetoprotein (AFP) were done at the Department of Biochemistry, BSMMU, while abdominal ultrasound and upper gastrointestinal (GI) endoscopy were done at the Department of Radiology and Imaging and Department of Hepatology, BSMMU respectively.

Data were collected with a structured form filled by the investigator after interviewing with the sample unit and were presented as tables. Statistical analysis was carried out by the software SPSS version 23.

\section{RESULTS}

It was observed that more than two third $(68.8 \%)$ patients belonged to age $\leq 50$ years in tenofovir group. The mean age was found $43.8 \pm 13.1$ years in tenofovir. The mean difference was not statistically significant $(p>0.05)$ of tenofovir. Altered level of consciousness was found $10(87.5 \%)$ in tenofovir group. Moderate ascites was found $11(68.8 \%)$ in tenofovir group. Encephalopathy was found 10(62.5\%) in tenofovir group. The tenofovir was not statistically significant $(p>0.05)$. It was observed that mean total count was found $10580.0 \pm 4818.6 / \mathrm{mm}^{3}$ in tenofovir group Mean serum bilirubin was found $19.8 \pm 7.4 \mathrm{mg} / \mathrm{dl}$ in tenofovir group. Mean Rank ALT was found 15.0 U/L in tenofovir group. Mean Rank AST was found $15.2 \mathrm{U} / \mathrm{L}$ in tenofovir group. Mean prothrombin time was found $22.1 \pm 3.3$ second in tenofovir group. Mean international normalized ratio was found $1.9 \pm 0.3$ in tenofovir group. Mean serum albumin was found $2.1 \pm 0.6 \mathrm{gm} / \mathrm{dl}$ in tenofovir group. Mean serum creatinine was found $0.98 \pm 0.27 \mathrm{mg} / \mathrm{dl}$ in tenofovir group. Mean serum sodium was found 133.4 \pm 5.3 $\mathrm{mmol} / \mathrm{l}$ in tenofovir. Mean serum potassium was found $4.1 \pm 0.7 \mathrm{mmol} / \mathrm{l}$ in tenofovir group. Mean MELD score was found $25.0 \pm 3.1$ in tenofovir group. Mean Child Pugh score was found $12.1 \pm 1.3$ in tenofovir group. The mean difference were not statistically significant ( $p>0.05)$ of tenofovir. HBeAg was found $12(37.5 \%)$ patients in tenofovir group. HBV DNA was found $16(50.0 \%)$ patients belonged to HBV DNA>20000 $\mathrm{IU} / \mathrm{ml}$ in tenofovir group. Mean Rank HBV DNA was found $16.8 \mathrm{IU} / \mathrm{ml}$ in tenofovir group. The in tenofovir was not statistically significant $(\mathrm{p}>0.05)$. 


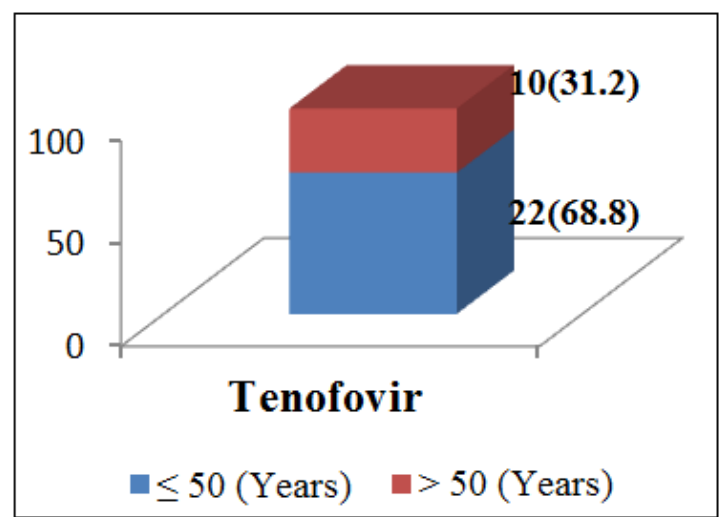

Fig-1: Age distribution of the study patients $(n=32)$

Table-1: Distribution of the study patients bysymptom and sign $(n=32)$

\begin{tabular}{|l|l|l|}
\hline \multirow{2}{*}{ Symptom } & \multicolumn{2}{|l|}{ Tenofovir } \\
\cline { 2 - 3 } & n & \% \\
\hline Yellowish eye and urine & 32 & 100.00 \\
\hline Abdominal swelling and /or legs swelling & 32 & 100.00 \\
\hline Altered level of consciousness & 28 & 87.5 \\
\hline Ascites & \multicolumn{3}{|l|}{} \\
\hline Mild & 10 & 31.3 \\
\hline Moderate & 22 & 68.8 \\
\hline Severe & 0 & 0.0 \\
\hline Encephalopathy & \multicolumn{2}{|l}{} \\
\hline Present & 20 & 62.5 \\
\hline Absent & 12 & 37.5 \\
\hline
\end{tabular}

Table-2: Baseline investigation of the study patients $(n=32)$

\begin{tabular}{|c|c|c|c|}
\hline \multirow[t]{2}{*}{ Symptom } & \multicolumn{2}{|c|}{ Tenofovir } & \multirow{2}{*}{$\begin{array}{l}P \\
\text { value }\end{array}$} \\
\hline & Mean & \pm SD & \\
\hline Total count $\left(/ \mathrm{mm}^{3}\right)$ & 10580.0 & \pm 4818.6 & \multirow[t]{2}{*}{${ }^{\mathrm{a}} 0.792^{\mathrm{ns}}$} \\
\hline Range (min-max) & 2010 & -20000 & \\
\hline Serum bilirubin $(\mathrm{mg} / \mathrm{dl})$ & 19.8 & \pm 7.4 & \multirow[t]{2}{*}{${ }^{\mathrm{a}} 0.353^{\mathrm{ns}}$} \\
\hline Range (min-max) & 9.8 & -33.5 & \\
\hline $\mathrm{ALT}(\mathrm{U} / \mathrm{L})$ & & & \multirow[t]{3}{*}{${ }^{\mathrm{b}} 0.366^{\mathrm{ns}}$} \\
\hline Mean Rank & 15.0 & 18.0 & \\
\hline Sum of Ranks & 240.0 & 288.0 & \\
\hline AST (U/L) & & & \multirow[t]{3}{*}{${ }^{\mathrm{b}} 0.429^{\mathrm{ns}}$} \\
\hline Mean Rank & 15.2 & 17.8 & \\
\hline Sum of Ranks & 243.0 & 285.0 & \\
\hline Prothrombin time $(\mathrm{sec})$ & 22.1 & \pm 3.3 & \multirow[t]{2}{*}{${ }^{\mathrm{a}} 0.459^{\mathrm{ns}}$} \\
\hline Range (min-max) & 17.3 & -29.5 & \\
\hline INR & 1.9 & \pm 0.3 & \multirow[t]{2}{*}{${ }^{\mathrm{a}} 0.353^{\mathrm{ns}}$} \\
\hline Range (min-max) & 1.5 & -2.5 & \\
\hline Serum albumin $(\mathrm{gm} / \mathrm{dl})$ & 2.1 & \pm 0.6 & \multirow[t]{2}{*}{${ }^{\mathrm{a}} 0.313^{\mathrm{ns}}$} \\
\hline Range (min-max) & 1.2 & -3.2 & \\
\hline Serum creatinine $(\mathrm{mg} / \mathrm{dl})$ & 0.98 & \pm 0.27 & \multirow[t]{2}{*}{${ }^{\mathrm{a}} 0.215^{\mathrm{ns}}$} \\
\hline Range (min-max) & 0.3 & -1.3 & \\
\hline Sodium (mmol/l) & 133.4 & \pm 5.3 & \multirow[t]{2}{*}{${ }^{\mathrm{a}} 0.708^{\mathrm{ns}}$} \\
\hline Range (min-max) & 122 & -141 & \\
\hline Potassium (mmol/l) & 4.1 & \pm 0.7 & \multirow[t]{2}{*}{${ }^{\mathrm{a}} 0.199^{\mathrm{ns}}$} \\
\hline Range (min-max) & 3.2 & -5.9 & \\
\hline MELD score & 25.0 & \pm 3.1 & \multirow[t]{2}{*}{${ }^{\mathrm{a}} 0.114^{\mathrm{ns}}$} \\
\hline Range (min-max) & 19.0 & -30.7 & \\
\hline Child-Turcotte Pugh score & 12.1 & \pm 1.3 & \multirow[t]{2}{*}{${ }^{\mathrm{a}} 0.841^{\mathrm{ns}}$} \\
\hline Range (min-max) & 10 & -14 & \\
\hline
\end{tabular}




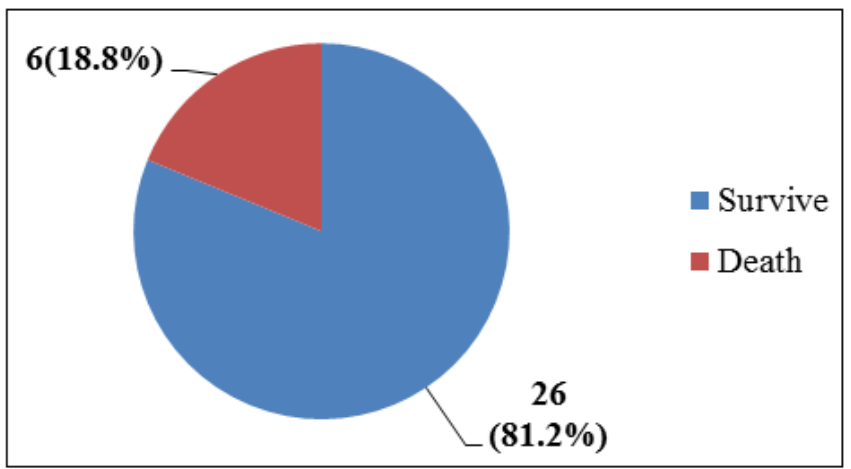

Fig-2: Outcome Efficacy of tenofovir in patients with acute on chronic hepatitis $B$ liver failure (n=32)

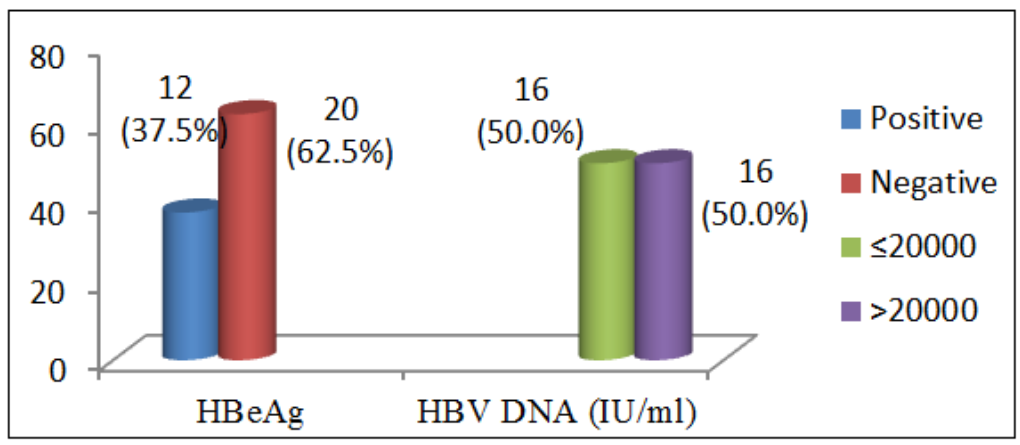

Table-3: Distribution of the study patients by HBeAg and HBV DNA (n=32)

\section{DISCUSSION}

In this study it was observed that more than two third $11(68.8 \%)$ patients belonged to age $\leq 50$ years in tenofovir group and $13(81.3 \%)$ in entecavir group. The mean age was $43.8 \pm 13.1$ years in tenofovir group and $44.2 \pm 12.3$ years in entecavir group. No difference was found between the two groups. Similar age distribution has been seen in clinical trials involving HBV-ACLF patients by Lai et al., [5], Garg et al., [6] and Chang et al., [7]. In this current series male predominance was seen in both groups, (93.7\%) in tenofovir group and $81.3 \%$ in entecavir group. Similar observations regarding male predominance has also been observed in studies by Guzelbulut et al., [8], Garg et al., [6], Bommel et al., [9], Lai et al., [5] and Chang et al., [7]. In this series all baseline investigation reports were almost similar between the two groups and no significant $(p>0.05)$ difference was observed. Similar observations were made in studies with HBV related ACLF patients by Garg et al., [6] and Chang et al., [7]. Similarly no significant difference $(p>0.05)$ was seen in the size of oesophagealvarices of the patients in the two groups which is similar to the study by Garg et al., [6]. However there are few direct comparisons between entecavir and tenofovir in decompensated cirrhosis. In a randomized, controlled study by Liaw et al., [10] of 112 patients with mildly decompensated cirrhosis (average MELD score 11, CTP score 7), HBV DNA at week 48 was undetectable in $71 \%$ of tenofovir-treated patients and $73 \%$ treated with entecavir. In this present study in tenofovir patients, mean Child Pugh score was 12.1 \pm 1.3 in pre-treatment and $7.2 \pm 1.3$ at 90 days, while mean MELD score was $25.0 \pm 3.1$ in pre-treatment and 9.3 \pm 3.2 at 90 days. It was observed that S. Bilirubin, INR, ALT, Child-Turcotte Pugh score and MELD score had significant $(\mathrm{p}<0.05)$ decline at 90 days in tenofovir group. Serum albumin increased significantly $(\mathrm{p}<0.05)$ at 90 days in this group, which indicates that the present study showed tenofovir significantly improves serum bilirubin, serum albumin, Child-Turcotte Pugh (CTP) and model for end stage liver disease (MELD) scores 3 months after therapy. In the surviving patients Garg et al., [6] found there was a significant improvement in the, serum bilirubin, Child-Turcotte Pugh (CTP) and model for end stage liver disease (MELD) scores in the tenofovir group, whereas these parameters did not change significantly in the placebo group. In this present study it was observed that in tenofovir group, all patients had detectable HBV DNA during pretreatment and 13 patients was undetected HBV DNA at 90 days $(\mathrm{p}<0.05)$. Garg et al., [6] reported that tenofovir significantly reduced HBV DNA levels from baseline $6.64 \log$ to $4.07(\mathrm{P}<0.05)$ at day 15 and to 3.04 at day 90 ( $\mathrm{P}<0.05)$. In the placebo group, out of the 10 surviving patients at day $15 \mathrm{HBV}$ DNA values could be obtained in nine. None of these nine patients had $>2 \mathrm{log}$ reduction at day 90 . In this present study it was observed that in entecavir arm, all patients had detectable HBV DNA at baseline and 6 had undetected HBV DNA at 90 days. The difference was statistically significant $(\mathrm{p}<0.05)$ between two groups. Bingliang et al., [11] showed all entecavir treated subjects achieved an undetectable HBV DNA level (<500 copies/ml; $100 \%$ vs $7.9 \%, \mathrm{p}<0.001)$. In the study by Guan and Lui [12] nearly $50 \%$ of the entecavir treated patients had a clinically significant decrease in their CTP score of $>2$ 
points. However 12 patients $(22.0 \%)$ showed no change in their CTP score and 4 patients had aggravation or their liver disease with worsening CTP scores. Similarly in another study, Lai et al., [13] reported that entecavir resulted in significantly higher rates of histologic, virologic and biochemical improvements compared to lamivudie in patients with HBeAg-negative chronic hepatitis B who had not previously received a nucleoside analogue. The findings are comparable with the current study. In this current study it was observed that at 90 days 12 patients expired, out of whom 3 and 9 were respectively in tenofovir and entecavir groups. In tenofovir group cause of death was 1 had hepatorenal syndrome with hepatic encephalopathy, 1 hepatorenal syndrome with hepatic encephalopathy with hypokalaemia and 1 patient had hepatic encephalopathy with septiceamia. On the other hand, among the patients who expired in the entacavir group, 2 had hepatic encephalopathy with septiceamia, 3 hepatic encephalopathy with hepatorenal syndrome, 1 hepatorenal syndrome with septiceamia, 1 hepatic encephalopathy with hypokalaemia, 1 hepatorenal syndrome with hepatic encephalopathy with hyperkalaemia with hyponatremia and 1 had hepatic encephalopathy with hyponatremia. Similar observations have been made by Garg et al., [6] where $17(63.0 \%)$ patients died. Most 12 (82.0\%) deaths occurred because of development of multiorgan failure. Multiorgan failure resulted due to progressive liver failure, leading to renal failure (12/17 [70.0\%]) and hepatic encephalopathy (15/17 [88.0\%]). Most of these patients required mechanical ventilation as their respiratory parameters deteriorated. None of them could be weaned off the ventilator due to multiorgan failure and the patients succumbed to the disease.

In this present study it was observed that serum bilirubin level was also similar between two groups at pretreatment, $1^{\text {st }}$ follow up ( 7 days) and $2^{\text {nd }}$ follow up (14 days) but declined from pretreatment to $1^{\text {st }}$ follow up (7 days) and $2^{\text {nd }}$ follow up (14 days) in both groups. In $3^{\text {rd }}$ follow up, serum bilirubin was found $1.9 \pm 2.0 \mathrm{mg} / \mathrm{dl}$ in tenofovir group and $5.1 \pm 1.6 \mathrm{mg} / \mathrm{dl}$ in entecavir group $(\mathrm{p}<0.05)$. Serum bilirubin level declined significantly more in tenofovir group. Chen et al., [14] treated 55 patients with severe acute exacerbation of HBV leading to decompensation with entecavir, comparing them with 74 other patients who were not treated with nucleoside analogs. Entecavir greatly reduced $\mathrm{HBV}$ replication in different periods of therapy $(P<0.05)$, but the MELD score and liver function (ALT, albumin, bilirubin and PT) showed no significant change. These results suggested that shortterm suppression of HBV replication with entecavir may not slow down the progression of liver failure in patients with chronic severe hepatitis B.

\section{CONCLUSION}

For some people, Hepatatis B infection becomes chronic, meaning it lasts more than six months. Having chronic hepatitis B increases your risk of developing liver failure liver cancer or cirrhosis a condition that permanently scars of the liver. Tenofovir can treat hepatitis B very effectively in some people. In some situations, tenofovir is more effective. Research suggests tenofovir is a safe and effective long term reatment.

\section{REFERENCES}

1. Vizzutti F, Arena U, Laffi G, Marra F. Acute on chronic liver failure: From pathophysiology to clinical management. Trends in Anaesthesia and Critical Care. 2013 Jun 1;3(3):122-9.

2. Peng J, Gao W, Gupta BK, Liu Z, Romero-Aburto R, Ge L, Song L, Alemany LB, Zhan X, Gao G, Vithayathil SA. Graphene quantum dots derived from carbon fibers. Nano letters. 2012 Feb 8;12(2):844-9.

3. Perz JF, Armstrong GL, Farrington LA, Hutin YJ, Bell BP. The contributions of hepatitis B virus and hepatitis $\mathrm{C}$ virus infections to cirrhosis and primary liver cancer worldwide. Journal of hepatology. 2006 Oct 1;45(4):529-38.

4. Ohno T, Tsubota T, Nakamura Y, Sayama K. Preparation of S, C cation-codoped SrTiO3 and its photocatalytic activity under visible light. Applied Catalysis A: General. 2005 Jul 15;288(1-2):74-9.

5. Lai J, Yan Y, Mai L, Zheng YB, Gan WQ, Ke WM. Short-term entecavir versus lamivudine therapy for $\mathrm{HBeAg-negative} \mathrm{patients} \mathrm{with} \mathrm{acute-}$ on-chronic hepatitis B liver failure. Hepatobiliary Pancreat Dis Int. 2013;12(2):154-159.

6. Garg H, Sarin SK, Kumar M, Garg V, Sharma BC, Kumar A. Tenofovir improves the outcome in patients with spontaneous reactivation of hepatitis B presenting as acute-on-chronic liver failure [published correction appears in Hepatology. 2011 Sep 2;54(3):1114]. Hepatology. 2011;53(3):774780.

7. Chang TT, Gish RG, De Man R, Gadano A, Sollano J, Chao YC, Lok AS, Han KH, Goodman Z, Zhu J, Cross A. A comparison of entecavir and lamivudine for $\mathrm{HBeAg}$-positive chronic hepatitis B. New England Journal of Medicine. 2006 Mar 9;354(10):1001-10.

8. Güzelbulut F, Ovünç AO, Oetinkaya ZA, Senates E, Gökden Y, Saltürk AG, Sezikli M, Ozkara S, Cetinkaya F. Comparison of the efficacy of entecavir and tenofovir in chronic hepatitis B. Hepato-gastroenterology. 2012 Mar 1;59(114):477-80.

9. van Bömmel $\mathrm{F}$, de Man RA, Wedemeyer $\mathrm{H}$, Deterding K, Petersen J, Buggisch P, Erhardt A, Hüppe D, Stein K, Trojan J, Sarrazin C. Longterm efficacy of tenofovir monotherapy for hepatitis $\mathrm{B}$ virus monoinfected patients after failure of nucleoside/nucleotide analogues. Hepatology. 2010 Jan;51(1):73-80.

10. Liaw YF, Raptopoulou Gigi M, Cheinquer H, Sarin SK, Tanwandee T, Leung N, Peng CY, 
Myers RP, Brown Jr RS, Jeffers L, Tsai N. Efficacy and safety of entecavir versus adefovir in chronic hepatitis $B$ patients with hepatic decompensation: a randomized, open label study. Hepatology. 2011 Jul;54(1):91-100.

11. Wang ML, Rule S, Martin P, Goy A, Auer R, Kahl BS, Jurczak W, Advani RH, Romaguera JE, Williams ME, Barrientos JC. Targeting BTK with ibrutinib in relapsed or refractory mantle-cell lymphoma. New England Journal of Medicine. 2013 Aug 8;369(6):507-16.
12. Guan R, Lui HF. Treatment of hepatitis B in decompensated liver cirrhosis. Int J Hepatol. 2011; 2011:918017.

13. Lai YK, Zhou QY, Hu SM, Martin RR. Feature sensitive mesh segmentation. InProceedings of the 2006 ACM symposium on Solid and physical modelling, 2006 Jun 6 (pp. 17-25).

14. Chen J, Han JH, Liu C, Yu RH, Li FZ, Li QF, Gong GZ. Short-term entecavir therapy of chronic severe hepatitis B. Hepatobiliary Pancreat Dis Int. 2009 Jun 1;8(3):261-6. 